\title{
Comminuted supracondylar humeral fractures repaired with modified type 2 external skeletal fixators
}

\begin{abstract}
Humeral fractures are of great challenge in veterinary medicine, as they are often related to injuries and other organs. Surgical time is of paramount importance in these patients. External skeletal fixators exhibit great versatility, with preservation of fracture biology, and stability to promote bone healing. We report 19 cases using a modified type 2 external skeletal fixators successfully for treatment of humeral fractures in dogs and cats.
\end{abstract}

Keywords: dogs, cats, fractures, orthopedics, patients, skeletal fixators, traumatic injuries, surgical, animals
Volume I Issue 2 - 2017

\author{
Danilo Roberto Custódio Marques, ' Ana \\ Carolina Hespanha, ${ }^{2}$ José Fernando Ibañez ${ }^{3}$ \\ 'Veterinary Surgeon of Orthopedics and Soft tissue Surgery, \\ Public Veterinary Hospital, Brazil \\ ${ }^{2}$ Veterinary, Improvement in Small Animal Surgical Clinic, Public \\ Veterinary Hospital, Brazil \\ ${ }^{3}$ Small Animal Surgery Clinic, Federal University of Paraná, Brazil
}

\begin{abstract}
Correspondence: Danilo Roberto Custódio Marques, Veterinary Surgeon of Orthopedics and Soft tissue Surgery, Public Veterinary Hospital, Brazil, Tel +55 44998078 427,

Email danvetmarques@gmail.com
\end{abstract}

Received: June 23, 2017| Published: August 08, 2017

\section{Introduction}

Humeral fractures are common in clinical veterinary medicine. The humerus is surrounded by a significant muscle mass such that high energy trauma is required to cause a fracture of this bone. Trauma of this magnitude frequently results in other traumatic injuries particularly in the thoracic region. These comorbidities may prevent, or delay, surgical intervention and necessitate surgical time to be short. In such cases the use of modified type 2 External skeletal fixators (ESFs) may be beneficial. ${ }^{1-5}$ The modified type 2 ESF has some important advantages over open surgery (for internal fixation) including the biologic, biomechanical, technical, and functional advantages, the fact that well defined safe corridors exist, and the procedure causes minimal periosteal and endosteal damage, requires a short surgical time and provides good rigidity of fixation. ${ }^{1-8}$

Modified type 2 External skeletal fixators were used, with satisfactory results, in 19 supracondylar fractures $(12 \mathrm{dogs}$ and 7 cats), in animals ranging from 3 to $33 \mathrm{~kg}$, and from 6 months to 5 years of age. In all cases the closed technique was used for insertion of the pins, i.e. a scalpel blade (smallest possible) was used to incise the skin and muscle tissues were dissected using halsted forceps. A positive central thread pin and half pin placed via lateral access were placed in the distal fracture fragment and in the proximal fragment two half lateral pins and a half pin were placed from the cranial aspect (Pin in humeral cranial region). The transfixing pins were clamped to the aluminum bar to connect the cranial pin to the central thread pin. The pins were inserted at low speed rotation and cooled with $0.9 \%$ $\mathrm{NaCl}$. Post-operatively, the animal was medicated with cephalexin $(30 \mathrm{mg} / \mathrm{kg}, \mathrm{PO}, \mathrm{BID})$ for seven days, carprofen $(2.2 \mathrm{mg} / \mathrm{kg}, \mathrm{PO}, \mathrm{BID})$ for six days, tramadol (3mg/kg, PO, BID) for five days, and dipirona ( $25 \mathrm{mg} / \mathrm{kg}$, PO, TID) for seven days. The wound was lavaged with $0.9 \%$ saline every eight hours. Radiographs were repeated every 21 days until complete healing of the osteotomy was observed. Radiographic examination was performed every 21 days to evaluate the four A (alignment, apposition, apparatus and biological activity) recommended by AOVET. ${ }^{9}$

In all animals, bone healing occurred, with formation of secondary bone callus, over a variable time period (42 to 147 days). One of the advantages of this technique was the short surgical time (28 to 45 minutes). In two cases one of the pins had to be changed (62 and 73 days), and in some cases a small amount of inflammatory secretion was observed. The use of the aluminum bar allows the system to be lighter, favoring the support of the limb (good member support). The use of a maximum of four pins per bone fragment is recommended, and in these cases a positive central thread pin was used in the humeral condyles due to the type and location of the fracture and to increase the rigidity of fixation..$^{2-6}$ No problems were encountered when inserting the pins through the muscle layers. If the principles of ESF placement (preservation of biology, slow pin rotation to avoid bone necrosis, and maximum of 4pins per fragment) are followed, premature loosening of the implants can be avoided. ${ }^{3-7}$

Human patients with fracture develop the systemic inflammatory response syndrome now after fractures; we do not have these data quite evident in veterinary medicine. With this, the use of modified type 2 ESF was able to stabilize fractures with low surgical time and good stabilization, without triggering or stimulating inflammatory factors due to instability and muscle damage. Humeral fractures occur due to high energy trauma which often requires early surgical intervention to provide stabilization and bone fracture consolidation. The use of modified type 2 external skeletal fixators is an alternative for treatment of comminuted supracondylar humeral fractures which provides a short surgical time, good stabilization and biological osteosynthesis.

\section{Acknowledgements}

None. 


\section{Conflict of interest}

Author declares that there is no conflict of interest.

\section{References}

1. Bronson DG, Ross D, Toobs JP. Influence of the connecting rod on the biomechanical propations. Vet Comp Orthop Traumatol. 2003;16(2):82-87.

2. Harari J. Complications of external skeletal fixation. Vet Clin North Am Small Anim Pract. 1992;22(1):99-107.

3. Johnson AL, Egger EL, Eurell JC, et al. Biomechanics and biology of fracture healing with external skeletal fixation. Compend Contin Educ Pract Vet. 1998;20(4):487-498.

4. White DT, Bronson DG, Welch RD. A mechanical comparasion of veterinary linear external fixation systems. Vet Surg. 2003;32(6):507-514.
5. Williams EA, Rand JA, An $\mathrm{KN}$, et al. The early healing of tibial osteotomies stabilized by one-plane or two-plane external fixation. $J$ Bone Joint Surg Am. 1987;69(3):355-364.

6. Socie MJ, Rovesti GL, Griffon DJ. Biomechanical comparison of strategies to adjust axial stiffness of a hybrid fixator. Veterinary and Comparative Orthopaedics and Traumatology. 2012;25(3):224-230.

7. Dewey CW, Aron DN, Foutz TL, et al. Static strength evaluation of two modified unilateral external skeletal fixators. JSAP. 1994;35(4):211-216.

8. Lewis DD, Cross AR, Carmichael S, et al. Recent advances in external skeletal fixation. J Small Anim Pract. 2001;42(3):103-112.

9. Johnson AL, Houlton JEF, Vannini R. AO Principles of Fracture Management in the Dog and Cat. 1st edn. Davos, Switzerland: AO Publishing; 2005. p. 552. 